\title{
Fig Tree with Unrelated Fig Wasps
}

\author{
Aravind Krishnan K. ${ }^{1}$, Gayathri G. S. ${ }^{2}$, Sreedevi Amma ${ }^{3}$ \\ Department of Zoology, University College, Thiruvananthapuram
}

\begin{abstract}
A few non-agaonid wasps can enter figs to oviposit and effectively pollinate their fig hosts. In the study site (Karakulam, Thiruvananthapuram) Ficus hispida is pollinated by Ceratosolen marchali (Agaonidae). Two species of non-agaonid fig wasps, Philotrypesis pilosa and Apocrypta bakeri, also enter the fig to oviposit. Yet such wasps do not establish a mutualistic relationship with figs similar to that of agaonids. Using controlled experiments in which only one foundress per species was introduced to a fig, and compared the effect of the three wasp species on pollination. It has been recorded that foundress distribution in the fig female floral phase, and counted the number of wasps and seeds in the male floral phase, and found both non-agaonids are efficient pollinators too. The species of fig-entering non-agaonid wasps significantly reduced the number of $C$. marchali emerging from mature figs but had no effect on seed production. If P. pilosa or A. bakeri was introduced to figs containing one foundress of C. marchali, both non-agaonid wasps produced offspring. But without the $C$. marchali, $P$. pilosa and $A$. bakeri failed to reproduce. $P$. pilosa and $A$. bakeri depend on the agaonid, $C$. marchali, to make galls. Because they depend on the legitimate pollinator to make galls, neither P. pilosa nor A. bakeri is able to replace the agaonid wasp and establish a mutualistic relationship with their host fig tree.
\end{abstract}

Keywords: Ficus, mutualism, pollinating fig wasp, parasitism, non-pollinating fig wasps

\section{Introduction}

The remarkable association between plants of the genus Ficus and chalcid wasps of the family Agaonidae has been known for a long time. The interaction between fig wasps (Agaonidae) and their host fig trees (Ficus) is a striking example of an obligate plant-insect mutualism (Janzen, 1979; Weiblen, 2002). Seed production by fig trees is dependent on their highly specific pollinating fig wasps, whose offspring feed on a proportion of the fig ovules (Ramirez, 1970; Wiebes, 1979; Rasplus, 1996; Weiblen, 2002; Molbo et al., 2003). The relationship between Ficus and their pollinating fig wasps is widely regarded as a model system for studying co-evolution and co-speciation between insects and plants. Of the known species of figs, half of them are monoecious and the rests are functionally dioecoius. In monoecious species, both seeds and pollinators develop within the same syconium.

The genus Ficus, or better known as figs, are commonly known as a very important group of species in the tropical forest. Long have mankind known and used this plant species. Some civilization even considered the fruit (the sycone) of this species as the fruit of heaven (Chhetri, 2010). The figs are often known as keystone species that provides food source for herbivores all year long. This is possible because there are usually more than one species of fig in a single patch of tropical forest.

Usually we know this as the "one-to-one rule" that stated that one species of fig would only have one species of pollinator, and vice-versa. Those pollinator are a member of a group of wasps (order Hymenoptera) known as chalcids (Superfamily Chalcidoidea). And along with the pollinator, other chalcids also depend on the fig's syconia as a nursery ground. These other chalcids are usually known as parasites and they may not be bound to the "one-to-one rule". The parasites are usually more flexible on picking their host fig species (Corner, 1940; Hill, 1967; Boucek, 1998; Gullan \& Cranston, 2005). Though the "one-to-one rule" has been proven to be true, in 1985 Michaloud et al., stated that there could be more than one pollinating species for a fig species in an area. In 1992, Ware and Compton proved that a breakdown in the "one-to-one rule" could happen. Both researches were done in Africa, but in 2003 Parrish et al., proved that there have been natural hybridizations between species of dioecious figs in the Krakatau islands and western Java. For natural hybridization to occur in figs, a breakdown in pollinator specificity must first happen. This makes it interesting to find out whether the result of Parrish et al., 2003 is relevant: that the occurrence of symbiotic breakdowns may not be a rare case.

\section{Materials and Methods}

Ficus hispida (Fig. 1) is widely distributed in continental Asia. Trees grow upto 5-10 $\mathrm{m}$ in height. This tree, naturally occurs in tropical forest. It is also commonly seen in cities and villages as an ornamentaltree. Ficus hispida produces figs in synchronous crops with asynchrony between trees throughout the year. The pollinating wasp (Ceratosolen marchali) (Fig. 2a and 2b), two internally ovipositing nonagaonid species [Philotrypesis pilosa (Fig. 3a and 3b) and Apocrypta bakeri (Fig. 4a and 4b)] are associated with figs of $F$. hispida. A suitable tree was located in the site (Karakulam) and pre-receptive figs were selected for experimental introduction. The twigs bearing figs were encased in a fine-mesh nylon bag $(200 \times 200 \mathrm{~mm})$. Each bag was sealed tightly around the twig to prevent any fig wasps arriving naturally at the tree from pollinating the fig.

Mature figs were collected on other trees in the vicinity, stored in nylon bags, and the fig wasps allowed to emerge. Foundresses of $C$. marchali, $P$. pilosa and $A$. bakeri were collected separately in different bags. The nylon bags were first removed from the experimental twigs. Two kinds of experimental introductions were done: (1) One foundress of C. marchali, $P$. pilosa or A. bakeri was introduced directly into a fig. When introducing $P$. pilosa or A. bakeri, $C$. marchali was introduced first. Immediately when its head had entered the ostiole, the wasp was removed and $P$. pilosa or A. bakeri was allowed to enter the fig. (2) One foundress of $C$. marchali was first introduced, then immediately after her introduction, one foundress of P.pilosa or A. bakeri was introduced directly into same fig. When experimental introductions were finished, the bag was enclosed again on 


\section{International Journal of Science and Research (IJSR) \\ ISSN (Online): 2319-7064}

Index Copernicus Value (2015): 78.96 | Impact Factor (2015): 6.391

the branch with experimental figs and left until the figs were near maturity. Mature ninety-one figs were collected and the fig wasps allowed to freely emerge in the bag. The fig wasps including the wingless males were carefully collected and preserved in $75 \%$ ethanol. Each wasp was identified to species and counted. The numbers of seeds, aborted galls, and undeveloped flowers were also counted.

\section{Statistical analyses}

A paired-samples $t$-test was used to compare offspring of the three species of ovipositing fig wasps. Multiple regression models were used to analyse the effects of multiple factors on seed and pollinator production. All analyses were performed in the SPSS (13.0) program.

\section{Results}

Non-agaonid wasps can effectively pollinate the figs

C. marchali, $P$. pilosa or A. bakeri entered figs through the ostiole on the same days during the receptive phase, but $P$. pilosa and $A$. bakeri entered the fig always later than $C$. marchali. Figs pollinated by the foundress of $C$. marchali produced $40.67 \pm 52.31(n=18)$ seeds, and by P.pilosa or A.bakeri produced $70.33 \pm 50.67(n=15)$ seeds. The differences in the seeds produced by C. marchali, P.pilosa, and $A$. bakeri were not significant $(P=0.185)$. When foundresses of P.pilosa, or A. bakeri were singly introduced to a fig, no wasp offspring were produced. However, when P.pilosa and Apocrypta sp. were introduced to a fig already entered by $C$. marchali, both reproduced successfully. The abundance of Ceratosolen marchali per fig was significantly negatively affected by both internally ovipositing nonagaonid species $(P$. pilosa standardized slope $=-0.717, P<$ $0.001 ;$ A. bakeri, standardized slope $=-0.373, P<0.001)$. In contrast, seed production was not significantly affected (P.pilosa: standardized slope $=0.117, P=0.267 ;$ A . bakeri: standardized slope $=0.092, P=0.385)($ Table 1$)$.

Table 1: Impact of internally ovipositing non-agaonid species on the production of pollinators and seeds

\begin{tabular}{|c|c|c|c|c|}
\hline Variables & \multicolumn{2}{|c|}{ Seeds } & \multicolumn{2}{c|}{ Ceratosolen marchali } \\
\cline { 2 - 5 } & $\begin{array}{c}\text { Standard } \\
\text { slope }\end{array}$ & $\begin{array}{c}\mathrm{P} \\
\text { value }\end{array}$ & $\begin{array}{c}\text { Standard } \\
\text { slope }\end{array}$ & $\begin{array}{c}\mathrm{P} \\
\text { value }\end{array}$ \\
\hline P.pilosa & 0.117 & 0.267 & -0.717 & $<0.001$ \\
\hline A.bakeri & 0.092 & 0.385 & -0.373 & $<0.001$ \\
\hline
\end{tabular}

\section{Discussion}

Non-agaonid fig wasps that enter figs to oviposit are usually associated with passively pollinated Ficus species, and can be efficient pollinators (Jousselin et al., 2001). Previously studied cases revealed the natural history of internally ovipositing non-agaonid wasps was thought to be very similar to that of the agaonid wasps (Galil and Eisikowitch, 1970). Though, they do not establish a mutualistic relationship with their host fig similar to that of the associated agaonid wasp was unclear. In the study, even though P.pilosa, or A.bakeri effectively pollinated F. hispida under controlled experimental conditions, the two nonagaonid wasps could not reproduce independently, and depended on C. marchali. Although C. marchali, P.pilosa, or $A$. bakeri enter the figs on the same day (female floral phase), Ceratosolen marchali almost always enters first. These observations suggest that $P$. pilosa or A. bakeri are not gallmakers, but inquilines that depend on $C$. marchali to make the galls. Thus this study suggests why these nonagaonids cannot establish a mutualistic relationship with their host fig similar to that of the associated agaonid wasp.

\section{Summary and Conclusion}

1) Fig wasps utilized the sycone of figs as a place to rear their young.

2) A total of, one pollinator wasp species; Ceratosolen marchali, and two non-pollinating wasps; Philotrypesis pilosa, and Apocrypta bakeri were only found in the study area.

3) The "one-to-one rule" has been broken but the symbiosis of Ficus hispida with their respect pollinator, still retained.

4) The proportion of pollinator wasp was negatively correlated with fragmentation level; though due to symbiotic breakdown, a different pattern might be observed if the analysis was done according to the fig species and not the wasp species.

5) Symbiotic breakdown was found to be positively correlated with fragmentation level, though the relationship seems to not be a simple one.

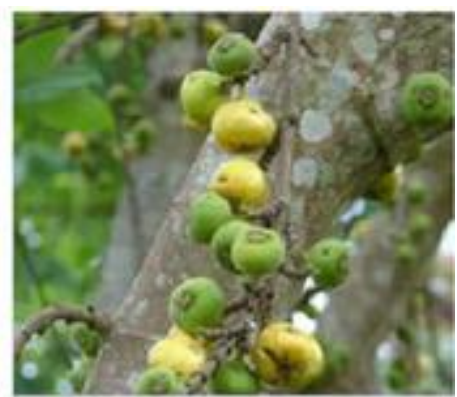

Figure 1 Ficus hispida 


\section{International Journal of Science and Research (IJSR) \\ ISSN (Online): 2319-7064}

Index Copernicus Value (2015): 78.96 | Impact Factor (2015): 6.391

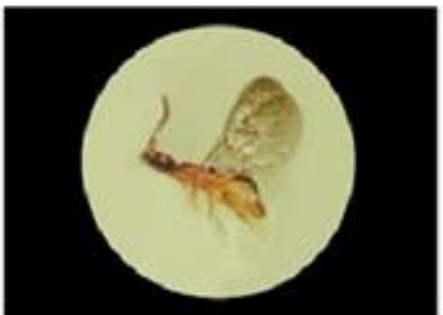

Figure 2 a Ceratosolen marchall female

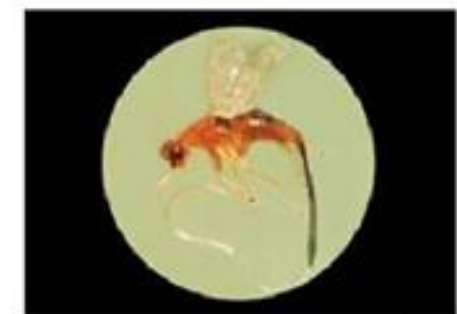

Figure 3a Philotnpesis pilosa female

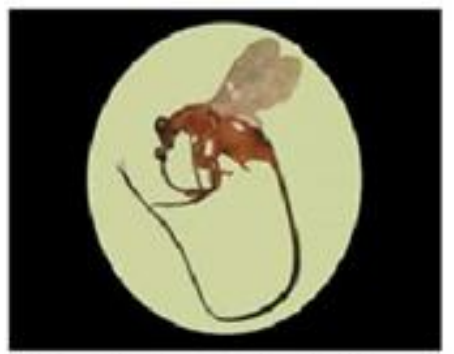

Figure 4a Apocrypta bakeri female

\section{References}

[1] Bouček, Z. 1988. Australasian Chalcidoidea (Hymenoptera): A Biosystematic Revision of Genera of Fourteen Families, with a Reclassification of Species. C.A.B. International Institute of Entomology, Ontario: i $+759 \mathrm{pp}$.

[2] Corner, E.J.H. 1940.Wayside trees of malaya. Government printing office, Singapore: vii +770 pp.

[3] Chhetri, R.B. 2010.Ethnobotany of moraceae in meghalaya north-east india. Kathmandu University $J$ Of Science, Engineering And Technology. 6 (1): 5-10.

[4] Galil, J. and Eisikowitch, D. 1970. The effect of SycophagasycomoriL. on the structure and development of syconia in Ficussycomorus. New.Phytol. 69: 103111.

[5] Gullan, P.J. and Cranston, P.S. 2005. The insects: an outline of entomology. Blackwell Publishing Ltd., Malden: xvii $+505 \mathrm{pp}$.

[6] Hill, D.S. 1967. Sycones (Ficus spp.) of Hong Kong. Hong Kong University Press, Hong Kong: pp. viii + 130.

[7] Janzen, D.H. 1979. How to be a fig. Annu. Rev. Ecol. Syst. 10: 13-51.

[8] Jousselin, E., Rasplus, J.Y. and Kjellberg, F. 2001. Shift to mutualism in parasitic lineages of the fig/fig wasp interaction. Oikos, 94: 287-294.

[9] Michaloud, G., Michaloud-Pelletier, S., Wiebes, J.T. and Berg,C.C. 1985. The co- occurrence of two pollinating species of fig wasp and one species of fig.Proceedings of the Koninklijke Nederlandse Akademie vanWetenschappen. 88: 93-119.

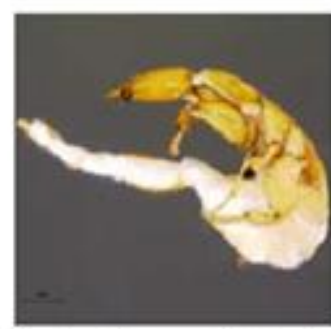

Figure 2b Cerutosolen marchall male

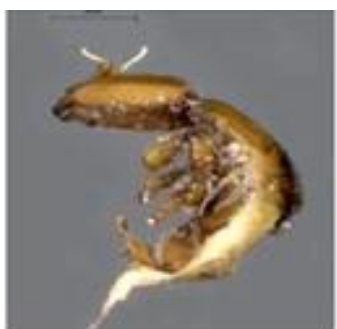

Figure $3 \mathrm{~b}$ Philotrypesis pilosa male

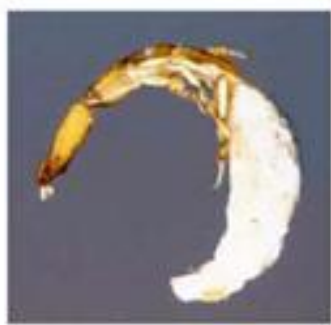

Figure $4 \mathrm{~b}$. Apocrypta bakerimale

[10] Molbo, D., Machado, C.A., Sevenster, J.G., Keller, L. and Herre, E.A. 2003. Cryptic species of fig-pollinating wasps: implications for the evolution of the fig-wasp mutualism, sex allocation, and precision of adaptation. Proc. Natl. Acad. Sci. USA. 100: 5867-5872.

[11] Parrish, T.L., Koelewijn, H.P.V and van Dijk, P.J. 2003. Genetic evidence for natural hybridization between species of dioecious Ficus on island populations. Biotropica. 35: 333-343.

[12] Ramirez, W.B. 1970. Host specificity of fig wasps (Agaonidae). Evolution. 24: 680-691.

[13] Rasplus, J.Y. 1996. The one-to-one species-specificity of the Ficus-Agaonidae mutualism: how casual, In The Biodiversity of African Plants (L.J.G van Burgt, X.M. van den Medenbrah de Rooy and J.M. van der Maesen, eds.), Dordrecht: Kluwer Academic. pp. 639-649.

[14] Ware, A.B. \& Compton, S.G. 1992. Breakdown of pollinator specificity in an African fig tree. Biotropica. 24(4): 544-549.

[15] Weiblen, G.D. 2002. How to be fig wasp.Annu. Rev. Entomol. 47: 229-230.

[16] Wiebes, J.T. 1979. Coevolution of figs and their insect pollinators. Annu. Rev. Ecol. Syst. 10: 1-12. 